\title{
Cereal rye cover crop effects on soil carbon and physical properties in southeastern Indiana
}

\author{
J.D. Rorick and E.J. Kladivko
}

\begin{abstract}
Cover crops can be a management practice used to improve soil health and increase resilience to extreme climate events in a typical midwestern corn-soybean (Zea mays L.Glycine max L.) rotation. This study was conducted as part of a large regional project with a goal of studying how to make corn-based cropping systems more resilient to climate stresses. A field site was established in southeastern Indiana to study the effects of a cereal rye (Secale cereale L.) cover crop on soil physical and chemical properties in a no-till corn and soybean rotation. Soil measurements included water stable soil aggregates using the wet sieving method, bulk density and water retention using intact cores, and soil organic carbon (SOC) and total nitrogen $(\mathrm{N})$. After four years of a cereal rye cover crop, wet soil aggregate mean weight diameter increased 55\% when compared to the no cover control in the 0 to $10 \mathrm{~cm}$ ( 0 to 4 in) depth and $29 \%$ in the 10 to $20 \mathrm{~cm}$ (4 to 8 in) depth. Bulk density, water retention, SOC, and total soil $\mathrm{N}$ showed no change between cover crop treatments. This research shows that a cereal rye cover crop can increase water stable aggregation in a relatively short time, but changes in other physical and chemical properties are more difficult to detect.
\end{abstract}

Key words: bulk density—cereal rye — cover crops—soil aggregation—soil carbon—water retention

In the Midwest, corn (Zea mays L.) is a dominant cash crop and is at least a part of almost every major cropping system, but questions have been raised about the sustainability and environmental impacts of corn-based cropping systems. In 2011 the USDA National Institute of Food and Agriculture (NIFA)-funded Cropping Systems Coordinated Agricultural Project, an eight state, transdisciplinary, five-year project, was begun to "evaluate the social, economic, and environmental impacts of climate variability on corn-based cropping systems" (Sustainable Corn 2016). One of the goals of the project was to investigate agronomic management practices and their effects on increasing the sustainability and resilience of these systems. Cover crops have been identified as a possible way to protect and improve soil physical properties and water quality (Blanco-Canqui et al. 2011; Kladivko et al. 2014 b), but research is still needed on how to integrate cover crops into corn-based cropping systems and to quantify the potential benefits and drawbacks of doing so. Cereal rye (Secale cereale L.) was used as the cover crop in this regional project because it has hypothesis that after four years of a cereal rye cover crop, there would be differences in soil physical and chemical properties between cover crop and no cover crop treatments on a poorly structured silt loam soil in Indiana, United States.

\section{Materials and Methods}

The field site was established at Purdue University's Southeast Purdue Agricultural Center near Butlerville, Indiana (39¹'32.88" $\left.\mathrm{N}, 85^{\circ} 32^{\prime} 24^{\prime \prime} \mathrm{W}\right)$, in 2011. Previous to the study, the field was in a conventionally tilled corn and soybean (Glycine max L.) rotation with soybean being the 2010 cash crop. In the spring of 2011 the field was tilled with a disk to a depth of $10 \mathrm{~cm}$ (4 in) and then with a field cultivator to a depth of $\sim 5 \mathrm{~cm}$ (2 in) prior to the overlay of the plots and treatments. Sixteen plots measuring $18 \times$ $365 \mathrm{~m}(60 \times 1,200 \mathrm{ft})$ were laid out in a 14 ha $(35 \mathrm{ac})$ field in a split plot design with each plot having a no-till corn and soybean rotation with or without a cereal rye cover crop. Treatments were corn with cereal rye, soybean with cereal rye, corn no cover, and soybean no cover replicated in each of four blocks. The cereal rye was drilled as soon as possible after cash crop harvest each year at a rate of $70 \mathrm{~kg} \mathrm{ha}^{-1}\left(63 \mathrm{lb} \mathrm{ac}^{-1}\right)$ and was chemically terminated in the spring with herbicide. In 2012, all treatments were terminated at the same time at least two weeks before corn planting. In the last three years of the study, it was decided to maximize cover crop growth so the termination timeline changed slightly. In the last three years, the plots going into corn (called "before corn") were terminated at least two weeks before cash crop planting. The no cover plots going into soybean (called "before soybean") were also sprayed at the same time as the before corn treatments to terminate any weeds present, so for three out of four treatments the termination timing is the same. The cereal rye in plots before soybean was allowed to grow until a few days before soybean planting in the last three years, in order to have greater biomass which might have greater impact on soil properties. Aboveground biomass amounts at the time of spring termination averaged across the four

Joseph D. Rorick is a graduate student in the Department of Agronomy at Purdue University in West Lafayette, Indiana. Eileen J. Kladivko is a professor in the Department of Agronomy at Purdue University in West Lafayette, Indiana. 
years of treatments were $1,900 \mathrm{~kg} \mathrm{ha}^{-1}(1,695$ $\mathrm{lb} \mathrm{ac}^{-1}$ ) for the cereal rye treatments and 545 $\mathrm{kg} \mathrm{ha}^{-1}\left(486 \mathrm{lb} \mathrm{ac}^{-1}\right)$ of weedy biomass for the no cover treatments. Crop and fertility management was performed in accordance with good agronomic practices and did not differ between cover crop treatments.

Soils at this field were mapped on site by Purdue pedologist Phillip Owens (personal communication, 2011). Soil types in the areas sampled were predominantly Nabb (fine-silty, mixed, active, mesic Aquic Fragiudalfs), Blocher (fine-silty, mixed, active, mesic Oxyaquic Hapludalfs), and Cincinnati (fine-silty, mixed, active, mesic, Oxyaquic Fragiudalfs) silt loams. This project was part of a larger regional project, and sampling protocols were standardized to ensure consistent methods across the regional network (Kladivko et al. 2014a). Soil measurements were taken within four weeks of planting the cash crop in odd years of the study (2011, 2013, and 2015), and sampling depths used were 0 to 10,10 to 20,20 to 40 , and 40 to 60 $\mathrm{cm}(0$ to 4,4 to 8,8 to 16 , and 16 to 24 in). Samples were taken in the quarter-row position of the corn rows $(\sim 19 \mathrm{~cm}$ [7.5 in] from the corn row) and midway between soybean drilled rows, avoiding any cereal rye plants if present. Wheel tracks were avoided where they were obvious, but due to different sizes and types of equipment used on the field, it was not always clear if a wheel track had been there or not.

Samples for aggregate stability were taken using a Giddings hydraulic probe $5.3 \mathrm{~cm}$ (2.1 in) in diameter in 2011 and 2015. These cores were cut into four depth increments (0 to 10,10 to 20,20 to 40 , and 40 to 60 $\mathrm{cm}$ [0 to 4,4 to 8,8 to 16 , and 16 to $24 \mathrm{in}])$, and two cores of each depth increment were composited per sample. Three samples were taken per plot, analyzed individually, and then averaged for each plot. Each sample was pushed through an $8 \mathrm{~mm}$ (0.3 in) sieve while still field moist and then air dried and sieved to remove the $<2 \mathrm{~mm}$ ( $0.1 \mathrm{in})$ fraction. Two $25 \mathrm{~g}$ (0.88 oz) subsamples of each sample were analyzed using the wet aggregate size distribution method (Nimmo and Perkins 2002), and an average mean weight diameter (MWD) was calculated for each depth.

Soil organic $\mathrm{C}$ and total soil nitrogen (N) samples were collected with a hydraulic probe similar to the aggregation samples and split into the same four depths. Six 5.3 $\mathrm{cm}$ (2.1 in) diameter cores were collected per plot, analyzed individually, and then averaged for each plot. Soil samples were air dried, hand ground to pass a $2 \mathrm{~mm}$ (0.1 in) sieve, and stored for subsampling and testing. An $\sim 10 \mathrm{~g}(0.35 \mathrm{oz})$ subsample from each core was further hand ground to pass a $150 \mu \mathrm{m}$ (0.0059 in) sieve for SOC and total $\mathrm{N}$ analysis. These subsamples were analyzed at the Iowa State University Soil and Plant Analysis Laboratory (Ames, Iowa) using the dry combustion method, and evolved carbon dioxide $\left(\mathrm{CO}_{2}\right)$ was measured using a LECO TruSpec (LECO Corporation, St. Joseph, Missouri) Inorganic $\mathrm{C}$ was negligible in this soil profile. In 2011, a subsample was taken from the $<2$ $\mathrm{mm}$ stored samples and sent to A\&L Great Lakes Laboratory (Fort Wayne, Indiana) to be analyzed for texture using the hydrometer method (Gee and Or 2002). Texture is unlikely to change over a four-year period, so it was determined only once on all plots at each depth (Kladivko et al. 2014a).

Bulk density was measured using the short core method as described by Grossman and Reinsch (2002) using a $6 \mathrm{~cm}$ (2.3 in) tall core $5.4 \mathrm{~cm} \mathrm{(2.1} \mathrm{in)} \mathrm{in} \mathrm{diameter} \mathrm{with} \mathrm{three}$ repetitions per depth in each plot. Samples were taken from the approximate center of each depth interval sampled to represent that depth increment. In 2011 and 2015 all four depths were sampled, and in 2013 only the 0 to $10 \mathrm{~cm}$ (0 to $4 \mathrm{in})$ and 10 to $20 \mathrm{~cm}$ (4 to 8 in) depths were sampled for water retention measurements and bulk density, due to the generally slow rate of change of these properties, especially in the lowest two depths.

Soil water retention was measured at five water potentials using sand tables and pressure pots according to the methods described by Dane and Hopmans (2002a, 2002b) The same cores used for bulk density measurements were used for water retention at saturation and $-4.9,-9.8$, and $-33 \mathrm{kPa}$ $(-0.71,-1.42$, and -4.79 psi). A bulk sample air dried and crushed to $<2 \mathrm{~mm}$ (0.1 in) was used for measurements at $-1,500 \mathrm{kPa}$ (-217.56 psi). Cores were gradually soaked to reach saturation and weighed, then placed on sand tables, allowed to equilibrate, and weighed to measure $-4.9 \mathrm{kPa}$ and $-9.8 \mathrm{kPa}$ water retention. Cores were then transferred to pressure pots to measure water retention at $-33 \mathrm{kPa}$ and then oven dried to obtain a dry mass for bulk density measurements. Aeration porosity was calculated as the difference between saturation and $-4.9 \mathrm{kPa}$ (Kohnke 1968). Water holding capacity
(WHC) was calculated as the difference between -9.8 and $-1,500 \mathrm{kPa}$.

Statistical analyses for all measurements were performed using SAS Version 9.4 software (SAS Institute Inc., Cary, North Carolina). Summary statistics and graphical data analysis were used to check for errors in the data and to see if a transformation was required (Box et al. 1978). The soil C data were square root transformed and aggregate stability data were log transformed prior to the analysis to make the data more normally distributed. Results are presented in back-transformed units. Each measure was analyzed as a split plot split block experimental design with cash crop used as the whole unit, cover crop as the split plot, and depth as the split block treatment. Error variances were dropped from the model where the majority of the variances were not significant at $p=0.25$. The MIXED procedure was used for the analysis of variance and an LSMeans separation test was performed on all significant effects $(p \leq 0.05)$.

Standardized protocols agreed upon by the USDA NIFA-funded Cropping Systems Coordinated Agricultural Project (Kladivko et al. 2014a) were followed; see paper for full explanation of methods. Research data and supporting metadata were uploaded to the team's central database with review and quality control performed by database managers to ensure data integrity and adherence to standardization (Herzmann et al. 2014). The data will be published at the National Agricultural Library (NAL) Ag Data Commons in 2017 (doi forthcoming). Data regarding comparisons not significantly different are not presented in this paper; however, the reader can access the data through the NAL.

\section{Results and Discussion}

In June of 2011, prior to establishing cover crop treatments in fall of 2011, there were no differences in MWD among plots, indicating that the baseline values for plots that would receive rye cover versus no cover were the same (figure $1 ; p>0.05$ ). Aggregate size was greater in the upper soil depths than in the lower soil depths at the onset of the study and four years after treatments were instituted. After four years of a cereal rye cover crop wet soil aggregate MWD in the 0 to $10 \mathrm{~cm}$ (0 to 4 in) depth was 55\% larger with cover crop and 29\% larger in the 10 to $20 \mathrm{~cm}$ (4 to 8 in) depth when compared to the no cover 
treatments (figure 1, cover crop $\times$ depth $p$ $\leq 0.05$ ). No difference between cover crop treatments occurred below $20 \mathrm{~cm}$ and no difference between cash crops occurred at any depth in any year. Many studies have reported increased aggregate size or stability with the use of cover crops and continuous field cover (Villamil et al. 2006; Sainju et al. 2003; Rachman et al. 2003). The increased aggregation may be short-lived, however, as found by Linsler et al. (2016) in a greenhouse/incubation study where several brassicas or legumes were grown in the greenhouse and then terminated by freezing. After a 12-week incubation in a microcosm room following the cover crop termination, there was no difference in large macroaggregate concentration and total macroaggregates, indicating that differences in aggregation caused by some cover crops may be relatively short term. Tisdall and Oades (1982) reference the importance of actively growing roots and fungal hyphae on the stability of soil aggregates, adding strength to the argument for growing winter cover crops during a typically fallow period in a corn and soybean production system in order to help protect and improve the soil. The fibrous root system of cereal rye was likely one cause of the increased MWD (Benoit et al. 1962; Villamil et al. 2006), as well as fungal hyphae and the decaying organic matter from the dead roots (Tisdall and Oades 1982). Larger, more stable soil aggregates are better able to withstand erosive forces, allow for better water infiltration, and help to prevent surface compaction and runoff (Blanco-Canqui et al. 2011).

Texture in the four depths ranged from silt loam in the 0 to $10 \mathrm{~cm}$ ( 0 to 4 in) depth with $26 \%$ clay to silty clay loam in the 40 to $60 \mathrm{~cm}$ (16 to 24 in) depth with 33\% clay. This small difference in clay content indicates that the increased aggregate MWD at shallower depths compared with deeper depths is more likely due to the effects of the cash and cover crop roots on biological activity and soil organic matter concentration, rather than differences in clay content.

After four years of the cereal rye winter cover crop treatments, SOC was unaffected by crop rotation and cover crop treatment $(p>0.05)$. In 2015 the SOC concentration in the 0 to $10 \mathrm{~cm}$ ( 0 to $4 \mathrm{in}$ ) depth, when averaged between cash crops, was 15.05 and $14.02 \mathrm{~g} \mathrm{C} \mathrm{kg}^{-1}$ for cover and no cover, respectively $(p>0.05)$. Other researchers

\section{Figure 1}

Effects of a cereal rye cover crop on water stable aggregate mean weight diameter (MWD) in (a) 2011 and (b) 2015, averaged across cash crop as affected by a cover crop by depth interaction. Shown in back-transformed units. Depths with the same uppercase letters within a cover crop treatment are not significantly different at $p \leq 0.05$. Cover crop treatments with the same lowercase letters are not significantly different within a depth at the $p \leq 0.05$ level. The 2011 samples were taken in the spring after cash crop planting but before any cover crops had been established at the site.

(a) 4.0

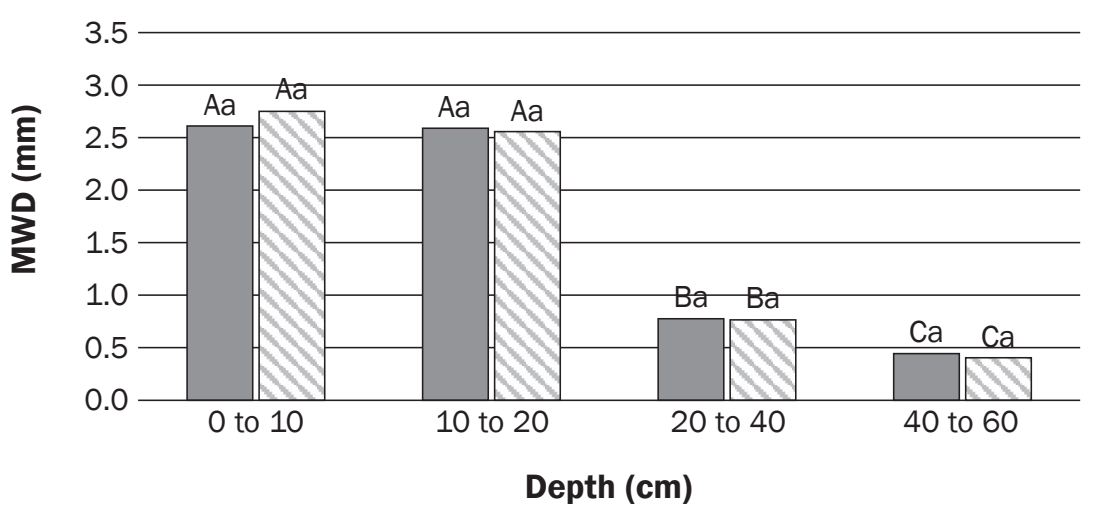

(b)

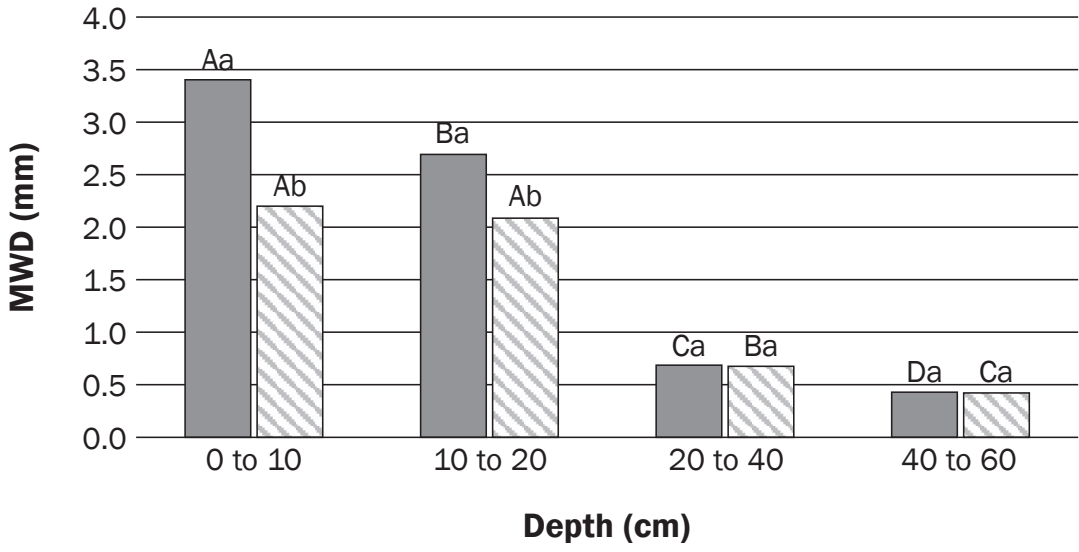

Legend

$\square$ Cereal rye $\quad \square$ No cover

have found little effect of cereal rye cover crop on SOC over a similar time frame (Eckert 1991; Kaspar et al. 2006); however, when measured after 10 years, Moore et al. (2014) was able to detect a $15 \%$ greater average soil organic matter content in the cereal rye treatment when compared to the no cover treatment. Kuo et al. (1997) found a 1 $\mathrm{g} \mathrm{kg}^{-1}$ higher SOC amount in a 0 to $15 \mathrm{~cm}$ (0 to 6 in) depth after eight years of cereal rye when compared to a no cover treatment, but both Eckert in Ohio (1991) and Jokela et al. in Wisconsin (2009) recorded no difference in SOC or soil organic matter after four years of cereal rye cover. A regional power analysis of minimum detectable differences (MDD) for SOC found a mean MDD of $3.38 \mathrm{~g} \mathrm{C}$ $\mathrm{kg}^{-1}$ for comparing two treatments with five replications at an $\alpha=0.05$ and a $\beta=0.15$ (Necpalova et al. 2014). With the SOC values being only about $1 \mathrm{~g} \mathrm{C} \mathrm{kg}^{-1}$ different between cover crop treatments in our study, it is not surprising that differences were not statistically significant due to the inherent variability of SOC. Organic C significantly decreased with depth (table 1), which is expected due to the predominance of roots in surface horizons and the deposition of cash crop and cover crop residues on the soil surface without incorporation from tillage. 
The distribution of total soil $\mathrm{N}$ mirrors that of organic C (table 1) with the highest values at the surface and decreasing with depth in all years. Soils sampled in soybean had lower soil $\mathrm{N}$ than in corn: $0.94 \mathrm{~g} \mathrm{~N} \mathrm{~kg}^{-1}$ and $1.03 \mathrm{~g} \mathrm{~N} \mathrm{~kg}^{-1}$, respectively, in 2011, and $1.01 \mathrm{~g} \mathrm{~N} \mathrm{~kg}^{-1}$ and $1.13 \mathrm{~g} \mathrm{~N} \mathrm{~kg}^{-1}$, respectively, in 2015 ( $p \leq 0.05)$. No differences were found between cover crop treatments for soil $\mathrm{N}$, with values in 2015 in the 0 to $10 \mathrm{~cm}(0$ to 4 in) depth of $1.64 \mathrm{~g} \mathrm{~N} \mathrm{~kg}^{-1}$ and $1.55 \mathrm{~g}$ $\mathrm{N} \mathrm{kg}^{-1}(p>0.05)$ for the cover crop and no cover crop treatments, respectively.

No differences in bulk density were found between cover crop treatments in any year $(p>0.05)$, and in the 0 to $10 \mathrm{~cm}$ ( 0 to $4 \mathrm{in})$ depth in 2015 for both cover and no cover, the values were $1.32 \mathrm{~g} \mathrm{~cm}^{-3}\left(82 \mathrm{lb} \mathrm{ft}^{-3}\right)$. In 2015 , bulk density was slightly greater in corn $\left(1.41 \mathrm{~g} \mathrm{~cm}^{-3}\right.$ [88 $\left.\left.\mathrm{lb} \mathrm{ft}^{-3}\right]\right)$ than in soybean $\left(1.38 \mathrm{~g} \mathrm{~cm}^{-3}\left[86 \mathrm{lb} \mathrm{ft}^{-3}\right]\right)$, similar to what was found in Iowa (Moore et al. 2014). Bulk density increased with depth in both years consistent with the decrease in SOC with depth. Over time we would expect soil bulk density to decrease due to the presence of the fibrous root system of the cereal rye. However, even after 13 years of cereal rye growth in a study in Maryland, no differences in bulk density were measured during the cash crop growing season, although there were some differences observed during the cover crop winter season (Steele et al. 2012). In our study the samples were all taken at a similar time of year in all three years. Care

\begin{tabular}{|c|c|c|c|}
\hline Year & Depth & $\begin{array}{l}\text { Soc } \\
\left(\mathrm{g} \mathrm{kg}^{-1}\right)\end{array}$ & $\begin{array}{l}\text { Tot N } \\
\left(\mathrm{g} \mathrm{kg}^{-1}\right)\end{array}$ \\
\hline \multirow[t]{4}{*}{2011} & 0 to 10 & $14.25 a$ & $1.46 a$ \\
\hline & 10 to 20 & $10.02 b$ & $1.22 \mathrm{~b}$ \\
\hline & 20 to 40 & $5.06 c$ & $0.76 c$ \\
\hline & 40 to 60 & $3.10 d$ & $0.51 d$ \\
\hline \multirow[t]{4}{*}{2013} & 0 to 10 & $13.00 a$ & $1.31 a$ \\
\hline & 10 to 20 & $8.68 b$ & $1.00 \mathrm{~b}$ \\
\hline & 20 to 40 & $4.16 c$ & $0.52 c$ \\
\hline & 40 to 60 & $3.12 d$ & $0.36 d$ \\
\hline \multirow[t]{4}{*}{2015} & 0 to 10 & $14.54 a$ & $1.60 a$ \\
\hline & 10 to 20 & $9.58 b$ & $1.25 b$ \\
\hline & 20 to 40 & $5.01 \mathrm{c}$ & $0.82 c$ \\
\hline & 40 to 60 & $3.65 d$ & $0.62 d$ \\
\hline
\end{tabular}

Note: Means followed by the same letter within a column and year are not significantly different at $p \leq 0.05$.

was also taken to sample in similar row positions on all plots and to avoid wheel tracks, but it is still possible that some less obvious wheel tracks were sampled, adding variability and making it very difficult to detect smaller changes due to the cover crop. Kaspar et al. (1995) found that trafficked interrows had up to a $36 \%$ higher bulk density $\left(1.36 \mathrm{Mg} \mathrm{m}^{-3}\right.$ [84 $\mathrm{lb} \mathrm{ft}^{-3}$ ]) when compared to untrafficked interrows $\left(1.09 \mathrm{Mg} \mathrm{m}^{-3}\left[68 \mathrm{lb} \mathrm{ft}^{-3}\right]\right.$ ) averaged across different tillage systems including chisel plow and no till, highlighting the need to plan sampling locations carefully.
Volumetric water content at saturation (0 $\mathrm{kPa}[0 \mathrm{psi}]$ ) had an inverse relationship with bulk density in 2011 and 2015 (table 2). Soils that are less dense have more total pore space that can be occupied by water at saturation. In both 2011 and 2015, the surface depth had significantly higher saturated water content than deeper depths consistent with a lower bulk density in the upper depths as previously discussed. Similarly, aeration porosity (the difference between $0 \mathrm{kPa}$ and $-4.9 \mathrm{kPa}[-0.71 \mathrm{psi}])$ did not differ with cover crop or cash crop although in 2011 and 2015 , depth was a significant factor with the greatest values in the 0 to $10 \mathrm{~cm}$ ( 0 to 4 in) depth (0.110 and 0.082 , respectively) and the lowest values in the 40 to $60 \mathrm{~cm}(16$ to 24 in) depth (0.025 in both years). Water retention at every water potential measured did not differ between cover crops nor between cash crops. Water retention of the 0 to $10 \mathrm{~cm}$ depth in 2011 and 2015 at $-4.9,-9.8$, and $-33 \mathrm{kPa}(-0.71,-1.42$, and $-4.79 \mathrm{psi})$ showed a significant difference when compared to the 40 to $60 \mathrm{~cm}$ depth except for -4.9 $\mathrm{kPa}$ in 2015. Volumetric water content at $-1,500 \mathrm{kPa}(-217.56 \mathrm{psi})$ in 2011 and 2015 showed significant differences between the top two depths and the bottom two depths. This may be due to a clay increase and the significant density increases with increasing depth resulting in more surface area for water retention at this approximation of wilting point. In the 0 to $10 \mathrm{~cm}$ depth, in 2015 the measured water potential values for the no

\section{Table 2}

Bulk density (BD) and volumetric water content at five water potentials, and water holding capacity (WHC*) with depth averaged across cover crop and cash crop within year.

\begin{tabular}{|c|c|c|c|c|c|c|c|c|}
\hline \multirow[b]{3}{*}{ Year } & \multirow[b]{3}{*}{ Depth } & \multirow[b]{3}{*}{$\mathrm{BD}\left(\mathrm{g} \mathrm{cm}^{-3}\right)$} & \multicolumn{6}{|c|}{ Volumetric water content $\left(\mathrm{cm}^{3} \mathrm{~cm}^{-3}\right)$} \\
\hline & & & \multicolumn{6}{|c|}{ Water potential (kPa) } \\
\hline & & & $\mathbf{0}$ & -4.9 & -9.8 & -33 & $-1,500$ & WHC \\
\hline \multirow{3}{*}{2011} & 10 to 20 & $1.40 \mathrm{~b}$ & $0.414 b$ & $0.356 a$ & $0.340 a$ & $0.319 a b$ & $0.134 a$ & $0.206 a$ \\
\hline & 20 to 40 & $1.44 \mathrm{~b}$ & $0.405 a b$ & $0.360 a b$ & $0.345 a$ & $0.330 \mathrm{~b}$ & $0.165 b$ & $0.180 a$ \\
\hline & 40 to 60 & $1.48 \mathrm{c}$ & $0.397 a$ & $0.372 b$ & $0.363 b$ & $0.355 c$ & $0.172 b$ & $0.192 a$ \\
\hline 2013 & 10 to 20 & $1.39 a$ & $0.420 a$ & $0.355 a$ & $0.339 a$ & $0.318 a$ & $0.122 a$ & $0.217 a$ \\
\hline \multirow[t]{4}{*}{2015} & 0 to 10 & $1.32 \mathrm{a}$ & $0.446 d$ & $0.364 \mathrm{c}$ & $0.346 b$ & $0.321 b$ & $0.125 a$ & $0.221 \mathrm{c}$ \\
\hline & 10 to 20 & $1.36 b$ & $0.416 c$ & $0.352 a$ & $0.336 a$ & $0.313 a$ & $0.129 a$ & $0.208 \mathrm{bc}$ \\
\hline & 20 to 40 & $1.42 \mathrm{c}$ & $0.406 b$ & $0.361 b c$ & $0.349 b c$ & $0.332 \mathrm{c}$ & $0.158 b$ & $0.192 a$ \\
\hline & 40 to 60 & $1.49 d$ & $0.395 a$ & $0.370 \mathrm{~cd}$ & $0.361 d$ & $0.350 d$ & $0.166 \mathrm{~b}$ & $0.196 a b$ \\
\hline
\end{tabular}

Note: Means followed by the same letter within a column and year are not significantly different at $p \leq 0.05$

*WHC calculated between -9.8 and $-1,500 \mathrm{kPa}$. 
cover treatment were all within $98 \%$ to $100 \%$ of the cover crop treatment $(p>0.05)$, and WHC was 0.224 and $0.219 \mathrm{~cm}^{3} \mathrm{~cm}^{-3}$ for the cover and no cover treatments, respectively. The WHC was not significantly different for cover crop or cash crop treatments in any year at $p \leq 0.05$, but WHC was significantly greater in cover crop treatments compared to no cover treatments at $p \leq 0.10$ in 2015 across all depths. In $2015 \mathrm{WHC}$ in the 0 to $10 \mathrm{~cm}$ depth was greater than in the 40 to 60 $\mathrm{cm}$ depth (table 2). These findings contrast with a study on a Mollisol in Illinois over a similar time period where slight differences were found in aeration porosity and WHC between cover crop treatments (Villamil et al. 2006). Additionally, Basche et al. (2016) found that after 13 years of cover crops, plant available water was $21 \%$ greater for the cover treatment compared to the no cover treatment in the 0 to $15 \mathrm{~cm}$ (0 to 6 in) depth on a loam soil in Iowa.

\section{Summary and Conclusions}

The addition of cereal rye as a winter cover crop to a no-till corn and soybean rotation can increase soil health benefits and improve soil physical properties over time. Soil aggregate stability in the 0 to $10 \mathrm{~cm}$ ( 0 to 4 in) depth was increased by $55 \%$ and in the 10 to $20 \mathrm{~cm}$ (4 to 8 in) depth by $29 \%$ after four years of cereal rye cover crop as compared to the control, which can help to improve water infiltration as well as help to protect against erosion and surface crusting. Bulk density, water retention, and SOC were unchanged by cover crop growth during that four year period, however. Increasing the amount of cover crop biomass produced within any year and over a greater number of years could increase the likelihood of maintaining or increasing SOC, which in turn could help to improve soil physical properties. Measuring changes in soil physical properties can be difficult due to the inherent spatial and temporal variation found in any soil, and differences may need to be large in order to be detectable within this natural variation.

\section{Acknowledgements}

This research is part of a regional collaborative project supported by the USDA National Institute of Food and Agriculture, Award No. 2011-68002-30190, Cropping Systems Coordinated Agricultural Project: Climate Change, Mitigation, and Adaptation in Corn-based Cropping Systems. Special thanks to the Southeast Purdue Agricultural Center staff for assistance with field management, Judy Santini for help with statistical analysis, and all of the graduate students involved with this field site throughout the project including: Jason Cavadini, Kaylissa Halter, Jessica Day, Sara Alford, Holly Hauenstein, Trevor Frank, and Nicole Benally.

\section{References}

Barnes, J.P., and A.R. Putnam. 1983. Rye residues contribute weed suppression in no-tillage cropping systems. Journal of Chemical Ecology 9:1045-1057.

Basche, A.D., T.C Kaspar, S.V. Archontoulis, D.B. Jaynes, T.J. Sauer, T.B. Parkin, and F.E. Miguez. 2016. Soil water improvements with the long-term use of a winter cover crop. Agricultural Water Management 172:40-50.

Benoit, R.E., N.A. Willis, and W.J. Hanna. 1962. Effect of rye winter cover crop on soil structure. Agronomy Journal 54:419-420.

Blanco-Canqui, H., M.M. Mikha, D.R. Presley, and M.M. Claassen. 2011. Addition of cover crops enhances no-till potential for improving soil physical properties. Soil Science Society of America Journal 75:1471-1482.

Box, G.E.P., W.G. Hunter, and J.S. Hunter. 1978. Simplification and increased sensitivity from transformation. Statistics for Experimenters: An Introduction to Design, Data Analysis, and Model Building, 231-239. Hoboken, NJ: John Wiley and Sons, Inc.

Dane, J.H., and J.W. Hopmans. 2002a. Pressure Plate Extractor. In Methods of Soil Analysis, Part 4, Physical Methods, eds. J.H. Dane and G.C. Topp, 688-690. Agronomy Monograph 5. Madison, WI: American Society of Agronomy and Soil Science Society of America.

Dane, J.H., and J.W. Hopmans. 2002b. Suction table. In Methods of Soil Analysis, Part 4, Physical Methods, eds. J.H. Dane and G.C. Topp, 692-697. Agronomy Monograph 5. Madison, WI: American Society of Agronomy and Soil Science Society of America.

Eckert, D.J. 1991. Chemical attributes of soils subjected to no-till cropping with rye cover crops. Soil Science Society of America Journal 55:405-409.

Gee, G.W., and D. Or. 2002. Particle-size analysis. In Methods of Soil Analysis, Part 4, Physical Methods, eds. J.H. Dane and G.C. Topp, 255-294. Agronomy Monograph 5. Madison, WI: American Society of Agronomy and Soil Science Society of America.

Grossman, R.B., and T.G. Reinsch. 2002. Bulk density and linear extensibility. In Methods of Soil Analysis. Part 4, Physical methods, eds. J.H. Dane and G.C. Topp, 201-228. Agronomy Monograph 5. Madison, WI: American Society of Agronomy and Soil Science Society of America.

Herzmann, D.E., L.J. Abendroth, and L.D. Bunderson. 2014. Data management approach to multidisciplinary agricultural research and syntheses. Journal of Soil and Water Conservation 69(6):180A-185A, doi:10.2489/ jswc.69.6.180A.

Jokela, W.E., J.H. Grabber, D.L. Karlen, T.C. Balser, and D.E. Palmquist. 2009. Cover crop and liquid manure effects on soil quality indicators in a corn silage system. Agronomy Journal 101:727-737.

Kaspar, T.C., S.D. Logsdon, and M.A. Prieksat. 1995. Traffic pattern and tillage system effects on corn root and shoot growth. Agronomy Journal 87:1046-1051.

Kaspar, T.C., T.B. Parkin, D.B. Jaynes, C.A. Cambardella, D.W. Meek, and Y.S. Jung. 2006. Examining changes on soil organic carbon with oat and rye cover crops using terrain covariates. Soil Science Society of America Journal 70:1168-1177.

Kladivko, E.J., M.J. Helmers, L.J.Abendroth, D. Herzmann, R. Lal, M.J. Castellano, D.S. Mueller, J.E. Sawyer, R.P. Anex, R.W. Arritt, B. Basso, J.V. Bonta, L.C. Bowling, R.M. Cruse, N.R. Fausey, J.R. Frankenberger, P.W. Gassman, A.J. Gassmann, C.L. Kling, A. Kravchenko, J.G. Lauer, F.E. Miguez, E.D. Nafziger, N. Nkongolo, M. O’Neal, L.B. Owens, P.R. Owens, P. Scharf, M.J. Shipitalo, J.S. Strock, and M.B.Villamil. 2014a. Standardized research protocols enable transdisciplinary research of climate variation impacts in corn production systems. Journal of Soil Water Conservation 69(6):532-542, doi:10.2489/ jswc.69.6.532.

Kladivko, E.J.,T.C. Kaspar, D.B.Jaynes, R. W. Malone, J. Singer, X.K. Morin, and T. Searchinger. 2014b. Cover crops in the upper Midwestern United States: Potential adoption and reduction of nitrate leaching in the Mississippi River basin. Journal of Soil and Water Conservation 69(4):279-291, doi:10.2489/jswc.69.4.279.

Kohnke, H. 1968. Soil Physics. New York: McGraw-Hill.

Kuo, S., U.M. Sainju, and E.J. Jellum. 1997. Winter cover crop effects on soil organic carbon and carbohydrate in soil. Soil Science Society of America Journal 61:145-152.

Linsler, D., M. Kaiser, R. Andruschkewitsch, C. Piegholdt, and B. Ludwig. 2016 Effects of cover crop growth and decomposition on the distribution of aggregate size fractions and soil microbial carbon dynamics. Soil Use and Management 32:192-199.

Moore, E.B., M.H. Wiedenhoeft, T.C. Kaspar, and C.A. Cambardella. 2014. Rye cover crop effects on soil quality in no-till corn silage-soybean cropping systems. Soil Science Society of America Journal 78:968-976.

Necpalova, M., R.P. Anex, A.N. Kravchenko, L.J. Abendroth, S.J. Del Grosso, W.A. Dick, M.J. Helmers, D. Herzmann, J.G. Lauer, E.D. Nafziger, J.E. Sawyer, P.C. Scharf, J.S. Strock, and M.B. Villamil. 2014. What does it take to detect a change in soil carbon stock? A regional comparison of minimum detectable difference and experiment duration in the north central United States. Journal of Soil Water Conservation 69(6):517-531, doi:10.2489/jswc.69.6.517.

Nimmo, J.R., and K.S. Perkins. 2002. Aggregate stability and size distribution. In Methods of Soil Analysis, Part 4, Physical Methods, eds. J.H. Dane and G.C. Topp, 317-328. Agronomy Monograph 5. Madison, WI:American Society of Agronomy and Soil Science Society of America. 
Rachman, A., S.H. Anderson, C.J. Gantzer, and A.L. Thompson. 2003. Influence of long-term cropping systems on soil physical properties related to soil erodibility. Soil Science Society of America Journal 67:637-644.

Sainju, U.M., W.F. Whitehead, and B.P. Singh. 2003. Cover crops and nitrogen fertilization effects on soil aggregation and carbon and nitrogen pools. Canadian Journal of Soil Science 83:155-165.

SAS Institute Inc. 2014. SAS 9.4. Cary, NC: SAS Institute Inc.

Steele, M.K., FJ. Coale, and R.L. Hill. 2012. Winter annual cover crop impacts on no-till soil physical properties and organic matter. Soil Science Society of America Journal 76:2164-2173.

Sustainable Corn. 2016. Sustainable Corn Homepage. https://sustainablecorn.org/.

Tisdall, J.M., and J.M. Oades. 1982. Organic matter and water-stable aggregates in soil. Journal of Soil Science 33:141-163.

Villamil, M.B., G.A. Bollero, R.G. Darmody, F.W. Simmons, and D.G. Bullock. 2006. No-till corn/ soybean systems including winter cover crops: Effects on soil properties. Soil Science Society of America Journal 70:1936-1944. 